This item was submitted to Loughborough's Research Repository by the author.

Items in Figshare are protected by copyright, with all rights reserved, unless otherwise indicated.

\title{
Ear prosthesis evaluation: specific absorption rate levels in the head due to different angles and frequencies of electromagnetic exposure
}

PLEASE CITE THE PUBLISHED VERSION

http://dx.doi.org/10.1080/09205071.2014.1003982

\section{PUBLISHER}

(C) Taylor and Francis Ltd.

\section{VERSION}

AM (Accepted Manuscript)

\section{PUBLISHER STATEMENT}

This work is made available according to the conditions of the Creative Commons Attribution-NonCommercialNoDerivatives 4.0 International (CC BY-NC-ND 4.0) licence. Full details of this licence are available at: https://creativecommons.org/licenses/by-nc-nd/4.0/

\section{LICENCE}

CC BY-NC-ND 4.0

\section{REPOSITORY RECORD}

Mat, Mohd H., M.F.A. Malek, W.G. Whittow, and Richard J. Bibb. 2019. "Ear Prosthesis Evaluation: Specific Absorption Rate Levels in the Head Due to Different Angles and Frequencies of Electromagnetic Exposure". figshare. https://hdl.handle.net/2134/16801. 


\section{This is the final author version}

M. H. Mat, F. Malek, W. G. Whittow, and R. J. Bibb, “Ear Prosthesis Evaluation:

Specific Absorption Rate Levels in the Head due to Different Angles and Frequencies of Electromagnetic Exposure,” J. Electromagn. Waves Appl., vol. Jan, 2015.

The final paper can be downloaded here:

http://www.tandfonline.com/doi/abs/10.1080/09205071.2014.1003982\#.VOH 8vmKVcY 


\title{
Ear Prosthesis Evaluation: Specific Absorption Rate Levels in the Head due to Different Angles and Frequencies of Electromagnetic Exposure
}

\author{
Mohd Hafizuddin Mat ${ }^{\mathrm{a} *}$, Mohd Fareq Abd Malek ${ }^{\mathrm{a}}$, William George Whittow ${ }^{\mathrm{b}}$ and Richard Bibb ${ }^{\mathrm{c}}$ \\ ${ }^{a}$ School of Electrical Systems Engineering, Universiti Malaysia Perlis (UniMAP), 02600 Arau, Perlis, \\ Malaysia; ${ }^{b}$ School of Electronic, Electrical and Systems Engineering, Loughborough University, LEICS \\ LE11 3TU, Loughborough, UK; ${ }^{c}$ Loughborough Design School, Loughborough University, LEICS LE11 \\ 3TU, Loughborough UK
}

(Received 29 September 2014; accepted 29 December 2014)

\begin{abstract}
This study presents a numerical analysis of the specific absorption rate in a head model exposed to electromagnetic fields when a real implant retained prosthetic ear is attached to the side of the head. A set of dipole antennas operating at 900 $\mathrm{MHz}, 1800 \mathrm{MHz}$ and $2100 \mathrm{MHz}$ were rotated to investigate the effect of frequency and polarisation. The maximum average $1 \mathrm{~g}$ and $10 \mathrm{~g}$ SAR have been presented to show the relative enhancement factor of the implant. A comparison of the mass averaged SAR in the head with the implanted ear prosthesis shows the $1 \mathrm{~g}$ SAR is doubled at $900 \mathrm{MHz}$ and $1800 \mathrm{MHz}$ with different polarisations.
\end{abstract}

Keywords: specific absorption rate; implant; electromagnetic wave; microwave energy; different frequency; electromagnetic field effects; electromagnetic wave absorption

\section{Introduction}

A wide variety of metal implants and reconstructive plates are used in head and neck reconstruction, but the close proximity of mobile phones to the ear makes the case of implant retained auricular prostheses particularly relevant to the effects of RF radiation. Loss of the external ear (the pinna) due to congenital abnormality, trauma, road accidents or cancer can be treated by reconstructive plastic surgery but many patients require or prefer prosthetic rehabilitation. Prosthetic ears may be retained by adhesives or mechanical means (attached to spectacle arms for example) but the gold standard treatment is osseointegrated implant retained prosthesis. Osseointegration involves inserting Titanium screws into bone. The bone grows around the implant resulting in a 
secure, load bearing implant that can support prostheses. Initially this was used in oral surgery to support dentures, but has since become commonly used in maxillofacial rehabilitation [1] .In maxillofacial prosthetics the implants are exposed through the skin using abutments. Typically, a number of implants are used to secure a prosthesis with a metal bar being attached to the implants. For auricular cases two implants of around 4 $\mathrm{mm}$ in length are usually used. The ideal position of the implants is shown in Figure 1. A visual explanation of the implant procedure can be found in [2]. A typical prosthetic ear consists of a rigid substructure made from acrylic and a silicone rubber prosthetic ear form. The ear form is moulded from colour matched silicone rubber incorporating the substructure. The substructure has metal clips embedded into it that attach the prosthesis to the bar. The implants and abutments are made from Titanium but the bar is typically made from gold alloy to avoid allergic reactions but other inert metals can be used. The bar and prosthesis is custom made for each individual patient by Maxillofacial Prosthetists and so each prosthetic will be unique however, the general arrangement is similar in most cases and the example used in this paper can be considered typical. It should be noted that these procedures are cosmetic and the patient can still hear with the damaged ear.

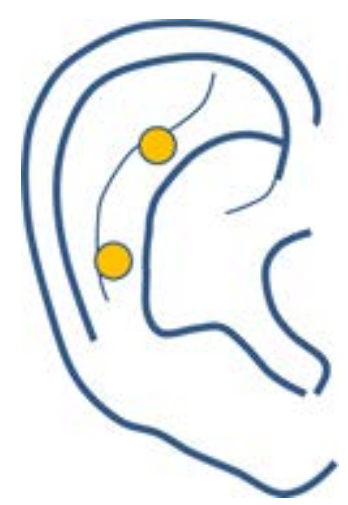

Figure 1. Ideal implant sites relative to the ear anatomy. 
There is public concern over the potential health risks due to exposure of radio frequency (RF) waves from devices like mobile phones. It is hypothesized that the metallic implants in the head could increase the local specific absorption rate (SAR). Previous research proved the coupling of electromagnetic (EM) field emitted by mobile phones with passive implant in the human body might cause notable enhancement in RF absorption under certain exposure conditions [3]-[20]. Parametric studies on metallic pins conducted in [21]-[23] verified that metallic pins that are approximately half a wavelength long, increased the SAR. In Virtanen's research [16] as the results of simple metallic models such as pins and rings implanted in the superficial layers of human body near to the mobile phone enhanced the SAR. Cooper's initial study [20] concludes that the value of RF absorption within a homogeneous head was significantly increased with the presence of metallic implants. Geometric representations of tongue piercings and dental braces have been considered in [24]. While previous papers have considered geometric shapes, this paper uses a 3D real implant shape.

A fundamental metric for specifying RF absorption by tissues is the SAR which can be calculated at any location in the tissue from the electric field (E):

$$
\operatorname{SAR}=\frac{\sigma|E|^{2}}{\rho}
$$

where $\sigma$ the conductivity $(\mathrm{S} / \mathrm{m}), \rho$ is the mass density $(\mathrm{kg} / \mathrm{m} 3)$, and $\mathrm{E}$ is expressed in root mean square (rms) value $(\mathrm{V} / \mathrm{m})$. The units are expressed as power absorbed per unit mass (W/kg). A recommendation from International Commission on Non-Ionizing Radiation Protection (ICNIRP) that the SAR should be averaged over 10 gram mass $\left(\mathrm{SAR}_{10 \mathrm{~g}}\right)$ and be less than $2 \mathrm{~W} / \mathrm{kg}$ [25]. The Institute of Electrical and Electronics Engineers (IEEE) has sets a slightly stricter limit value $\left(1.6 \mathrm{~W} / \mathrm{kg}\right.$ for $\mathrm{SAR}_{1 \mathrm{~g}}$ for general public) [26]. 
It is hypothesized that SAR levels might increase at certain angles of incidence and frequency when the resonant frequency matches the length of the implant and is parallel with the excitation. This numerical study analysed the effect in homogenous head model. The main objective is to compare the levels of SAR with and without the implant, depending on the incident frequency and the angle of RF source.

\section{MATERIALS AND METHOD}

\subsection{Simulations and RF Exposure}

The modelling and the calculations of EM fields were carried out using Computer Simulation Technology Microwave Studio (CST MWS). This software was run on a Dell Precision T5500 workstation, it accommodated with 6-core Intel Xeon X5506 series using 48GB memory. The SAR was calculated after the simulation completed using Time Domain Solver (TDM). The reference power defined as output power at 1 W (rms) using the IEEE/IEC 62704-1 averaging method. A density of $1 \mathrm{~g} / \mathrm{cm}^{-3}$ used to represent the head tissue density. Thus, cubic averaging volume shall be with side dimensions of $1.0 \mathrm{~cm}$ and $2.2 \mathrm{~cm}$ for $1 \mathrm{~g}$ cube and $10 \mathrm{~g}$ cube, respectively.

This paper aims to isolate the relative effect of the implant with different frequencies and polarisations. There are many different RF sources with different antennas positioned at different angles. Therefore, dipole antennas were used in this paper as a standardized source with a single polarisation. This in turn allows clear analysis of the behaviour of the implant. Three antennas were considered for the 900 , 1800 and $2100 \mathrm{MHz}$ frequencies. The antenna feed point located in a $1 \mathrm{~mm}$ air gap between the dipole halves constructed using perfect electric conductors (PEC). 


\subsection{Verification of the Simulation}

In this verification section, the simulation methodology was validated by replicating the results obtained by Kawai [27]. A half-wave $900 \mathrm{MHz}$ dipole antenna, a $200 \mathrm{~mm}$ cubic and a spherical head model were simulated. The characteristics of the head model are as follows: the electrical properties at $900 \mathrm{MHz}$ are the relative permittivity $\mathrm{\varepsilon r}=41.5$, the electrical conductivity $\sigma=0.97 \mathrm{~S} / \mathrm{m}$, and the density $\rho=1000 \mathrm{~kg} / \mathrm{m}^{3}$ [27]. The SAR is normalized to 1 Watt output. Table 1 shows, the simulated results of the present study provide a good agreement with the simulated results obtained from Kawai.

Table 1. Comparison of the calculated peak $\mathrm{SAR}_{10 \mathrm{~g}}$ with Kawai for the geometric head models.

\begin{tabular}{lcc}
\hline Head model & Kawai [27] & Present study \\
\hline Cube & 6.76 & 6.69 \\
Sphere & 6.31 & 6.36 \\
\hline
\end{tabular}

\subsection{Head Phantom}

The head phantom used in this paper was the Specific Anthropomorphic Mannequin (SAM) phantom head. This is the standard head for SAR investigations. This human head shaped phantom has a shell filled with a tissue simulating liquid (TSL) which represents the average dielectric properties of the human head. Its outer shell has a fixed relative permittivity of 3.7 with an electrical conductivity of $0.00016 \mathrm{~S} / \mathrm{m}$. Table 2 shows the permittivity and conductivity of the TSL.

Table 2. The dielectric properties of TSL.

\begin{tabular}{lcc}
\hline Frequency (MHz) & Relative Permitivity & Electrical Condutivity (S/m) \\
\hline 900 & 41.5 & 0.97 \\
1800 & 40.0 & 1.40 \\
2100 & 39.8 & 1.49 \\
\hline
\end{tabular}




\subsection{Ear Implantation}

For modelling, metallic bar constructed for patients will be located in the head at appropriate ear region. Its exact location is relative to the antihelix of the ear (just inside where the natural ear attaches to the head). Generally, this bar acts as the main support structure for ear prosthesis and as a connector to the clips attached in the prosthesis. The metal screws, abutments and metallic bar are shown in Figure 2. The dimensions of the implant are as follows: $\mathrm{a}=9.0 \mathrm{~mm} ; \mathrm{b}=7.6 \mathrm{~mm} ; \mathrm{c}=12.0 \mathrm{~mm} ; \mathrm{d}=8.4 \mathrm{~mm}$; $\mathrm{e}=6.0 \mathrm{~mm}$ and $\mathrm{f}=3.0 \mathrm{~mm}$.

In real clinical situations, the bar is made of gold. This bar was implanted or screwed 3 to $4 \mathrm{~mm}$ into the bone through the skin and positioned outside of the human tissue. There is a gap between the bar and the tissue approximately $3 \mathrm{~mm}$. The silicone ear will be clipped onto the bar; the clips are embedded in a rigid plastic which is in turn are embedded in the silicone rubber ear.

In this paper, the metallic bar was simulated as a PEC. Previous research by the authors has shown that the actual conductivity value of a highly conducting metal shape has negligible effect. The 4mm thick pinna of the SAM phantom head's shell was used to represent the silicone (or plastic) as the shape and electrical properties of the material were very similar. Figure 3 shows the location of the bar in the ear region covered with flat phantom's ear, while the screws and the abutments were inside the TSL. Figure 4 shows the view of the implant positioned relative to the SAM head. Note that all of the SAR simulations were performed with the dipole $5 \mathrm{~mm}$ from the ear. 

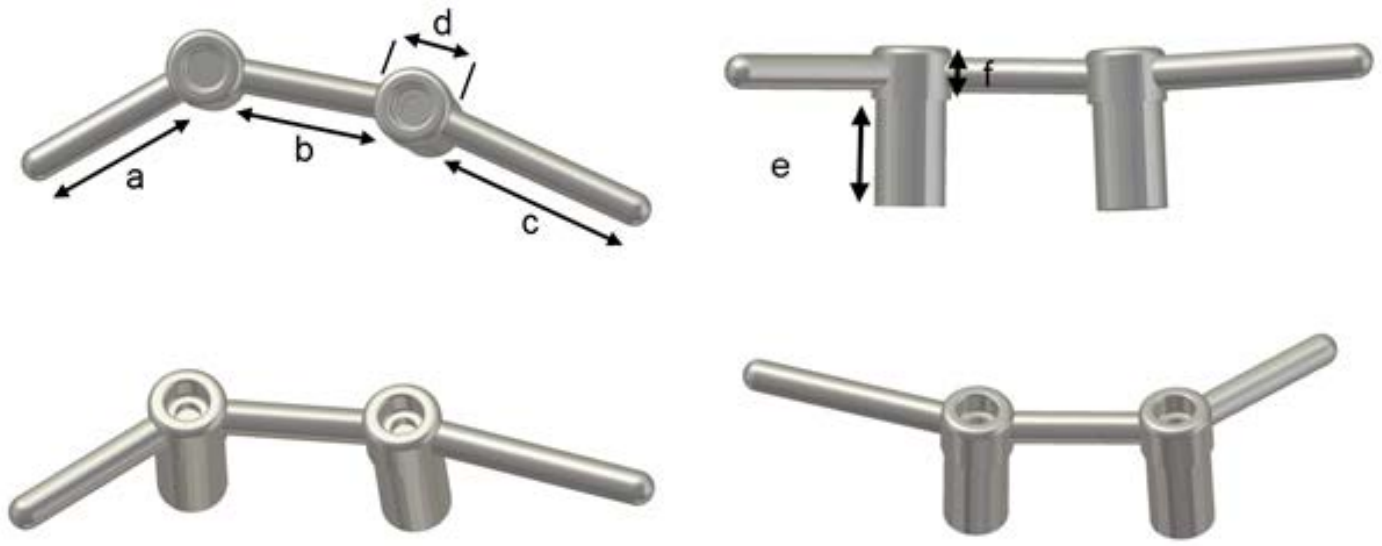

Figure 2. The implant as seen from different perspectives.

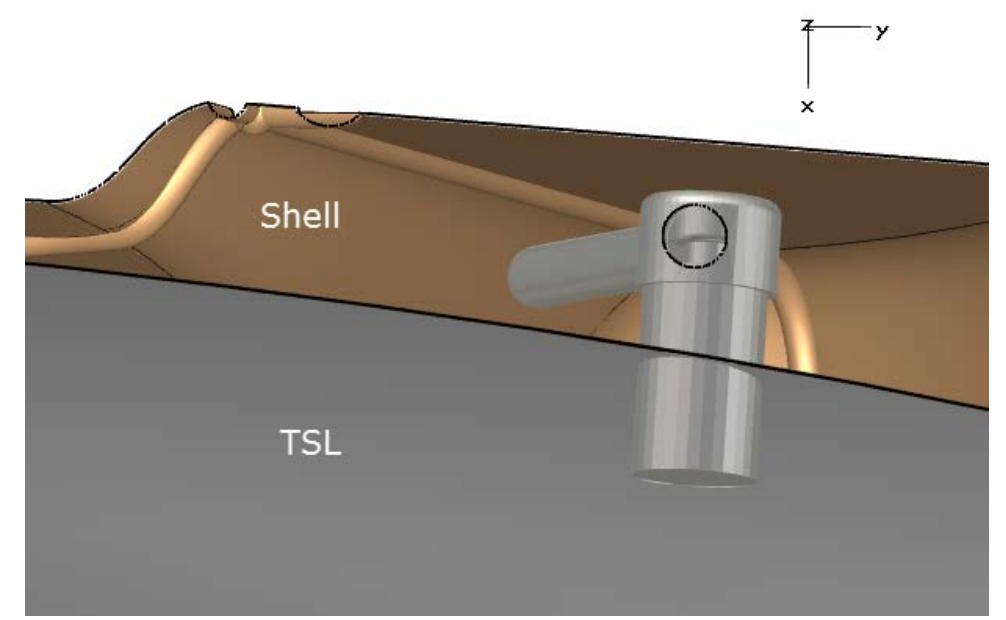

Figure 3. The position of the implant relative to the head.

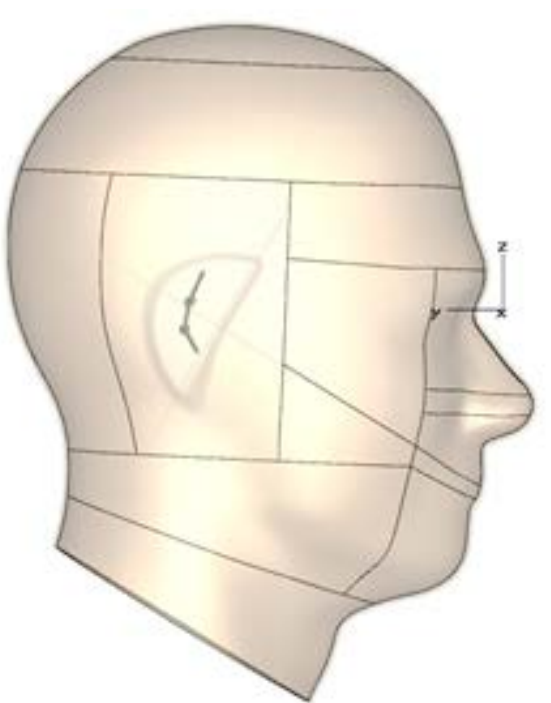

(a)

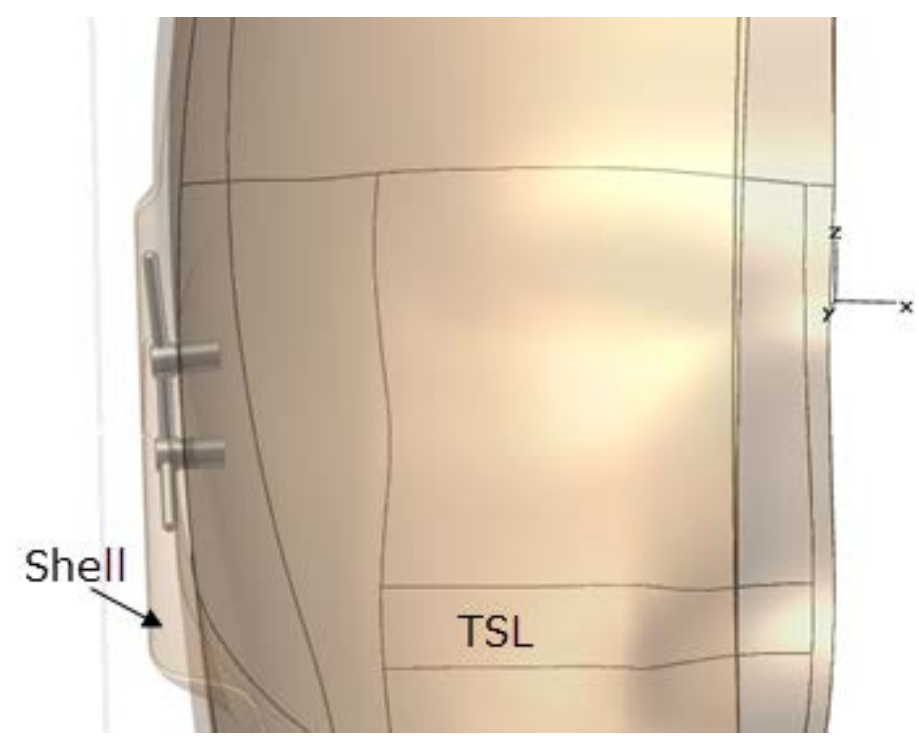

(b)

Figure 4. The SAM phantom head with implanted metallic bar at (a) side view and (b) front. 


\section{RESULTS AND DISCUSSION}

In order to study the effects of the metallic implant, the maximum mass averaged $\mathrm{SAR}_{1 \mathrm{~g}}$ and $\mathrm{SAR}_{10 \mathrm{~g}}$ in the head with and without implant was investigated at the frequency of $900 \mathrm{MHz}, 1800 \mathrm{MHz}$ and $2100 \mathrm{MHz}$. Initially, the dipole antenna was placed parallel to the z-axis and rotated clockwise from $0^{\circ}$ (vertical) to $180^{\circ}$ in steps of $5^{\circ}$ (and $90^{\circ}$ is parallel to the $y$-axis). The variations of dipole angle were to investigate the worst case situation. All the implant's parameters including location, size and material were fixed throughout this paper. The output power defined as $1 \mathrm{~W}$.

Figure 5 (a) and (b) compares the $900 \mathrm{MHz}$ results for $\mathrm{SAR}_{1 \mathrm{~g}}$ and $\mathrm{SAR}_{10 \mathrm{~g}}$ respectively. The peak of the averaged $\mathrm{SAR}_{1 \mathrm{~g}}$ was at $175^{\circ}$ with the implant. However, from $65^{\circ}$ to $120^{\circ}$ the implant has little effect on the mass averaged SAR. The $\mathrm{SAR}_{1 \mathrm{~g}}$ with the implant was increased from $0^{\circ}$ to $60^{\circ}$ and from $125^{\circ}$ to $180^{\circ}$. Meanwhile, in Figure 5 (b) the comparison $\mathrm{SAR}_{10 \mathrm{~g}}$ shows only small differences in the level of SAR.

The results of the correlation for $1800 \mathrm{MHz}$ exposure for both maximum $\mathrm{SAR}_{1 \mathrm{~g}}$ and $\mathrm{SAR}_{10 \mathrm{~g}}$ are summarised in Figure 6 (a) and (b). Specifically, there was significant higher $\mathrm{SAR}_{1 \mathrm{~g}}$ from $130^{\circ}$ to $145^{\circ}$ with the implant. While the variation in the maximum $\mathrm{SAR}_{10 \mathrm{~g}}$ with the implant was less significant.

Figure 7 (a) and (b) shows insignificant SAR level changes at $2100 \mathrm{MHz}$ with the implant as it was not of a resonant length. The SAR reduction mechanism is not implemented on present investigation.

Figure 8 shows a local enhancement in the SAR near the implant with dipole aligned at $0^{\circ}$ which explains the increased $\mathrm{SAR}_{1 \mathrm{~g}}$ results. The figure also shows that there is little change over a larger area, for example, in the $\mathrm{SAR}_{10 \mathrm{~g}}$ where the averaging size is approximately $2.2 \mathrm{~cm}$. 


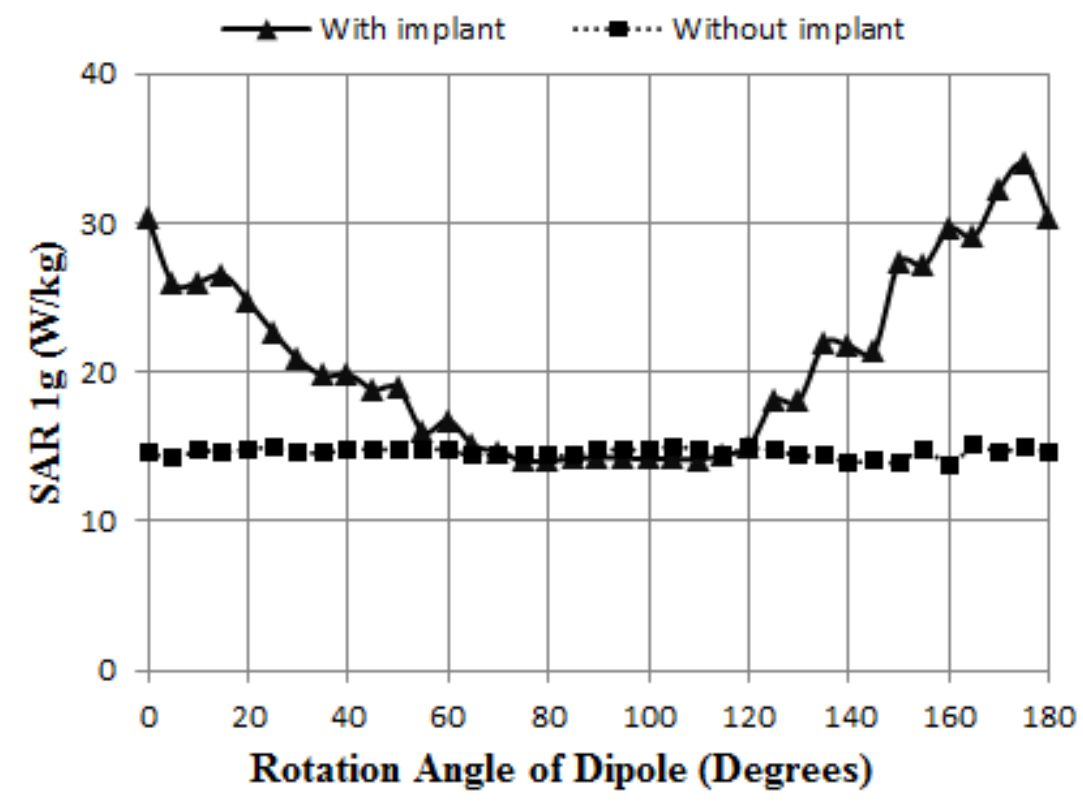

(a)

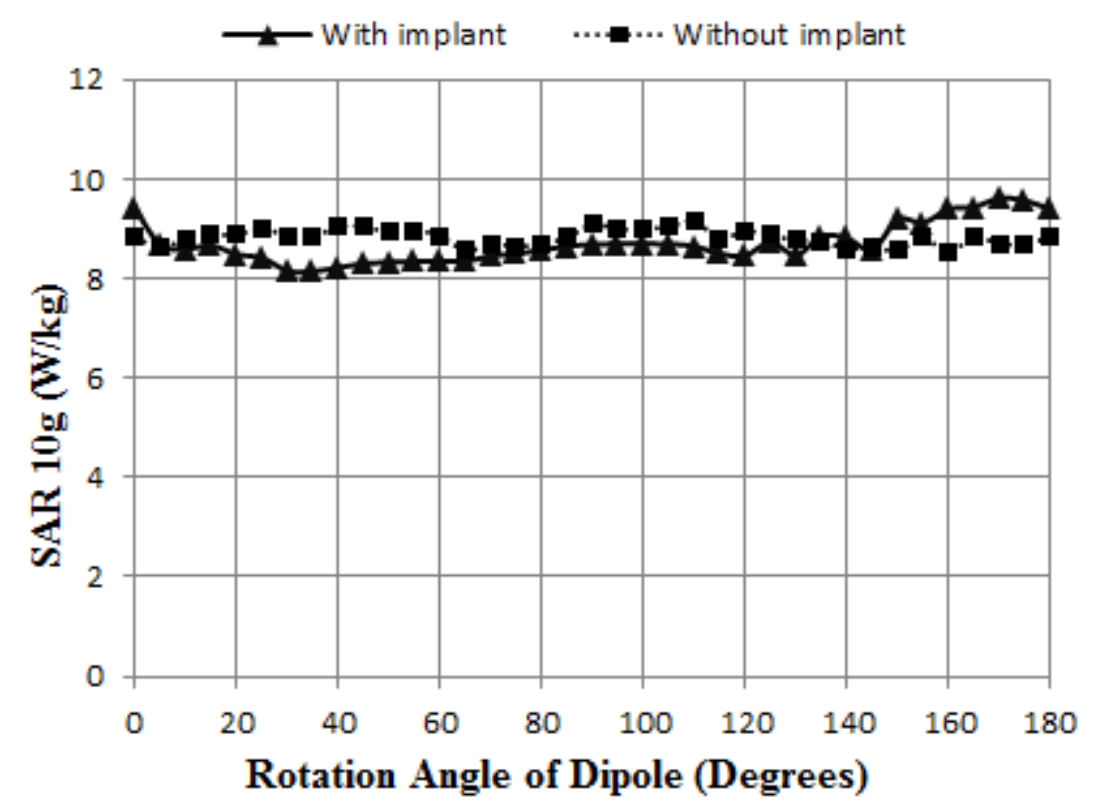

(b)

Figure 5. The maximum (a) $\mathrm{SAR}_{1 \mathrm{~g}}$ and (b) $\mathrm{SAR}_{10 \mathrm{~g}}$ as a function of dipole's rotation angle at $900 \mathrm{MHz}$. 


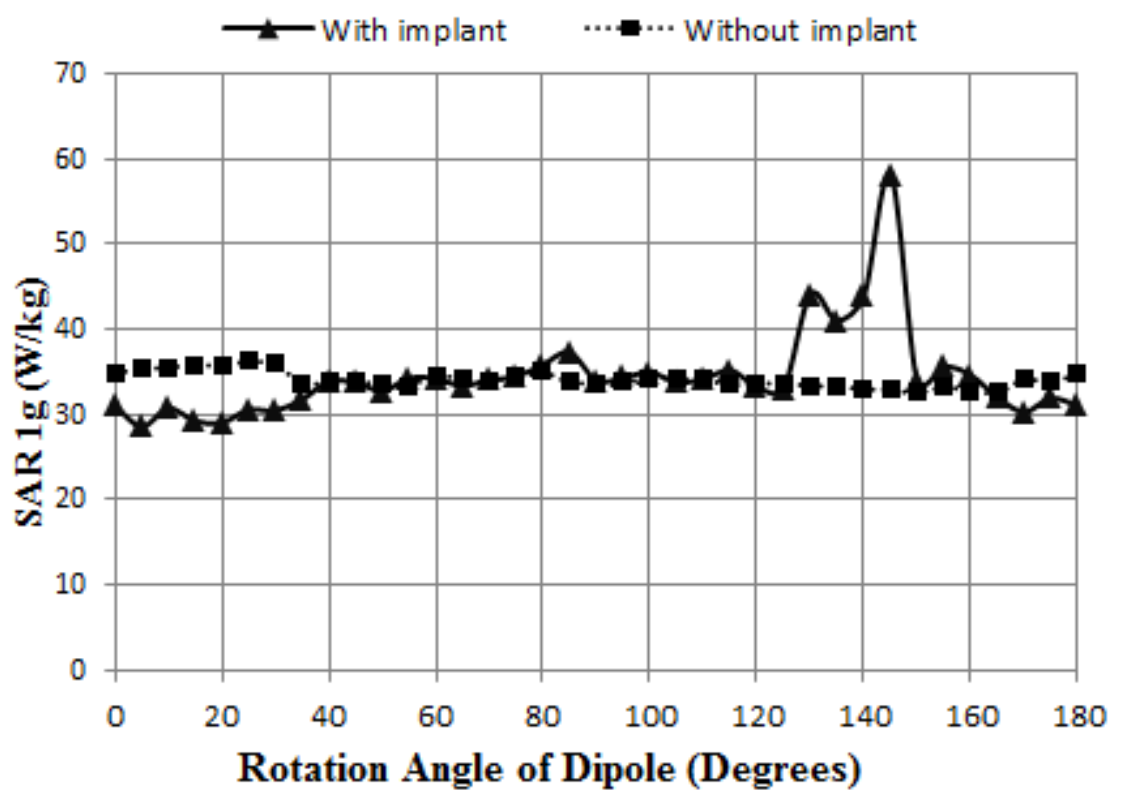

(a)

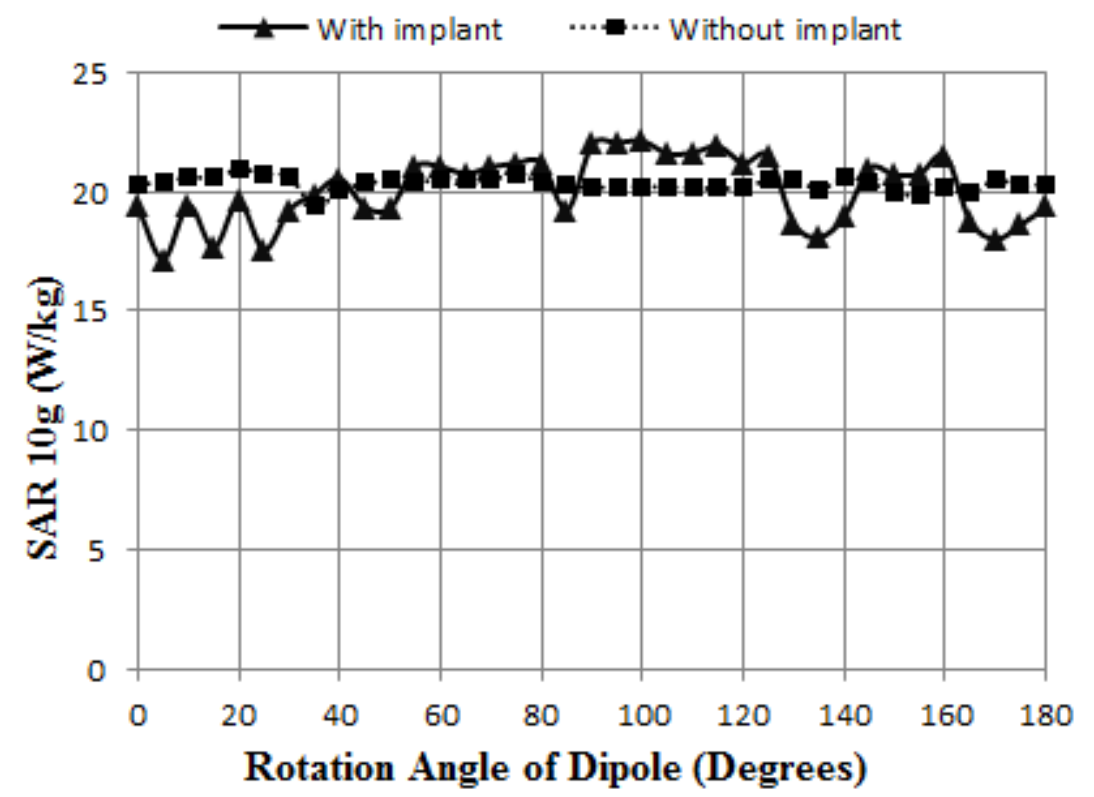

(b)

Figure 6. The maximum (a) $\mathrm{SAR}_{1 \mathrm{~g}}$ and (b) $\mathrm{SAR}_{10 \mathrm{~g}}$ as a function of dipole's rotation angle at $1800 \mathrm{MHz}$. 


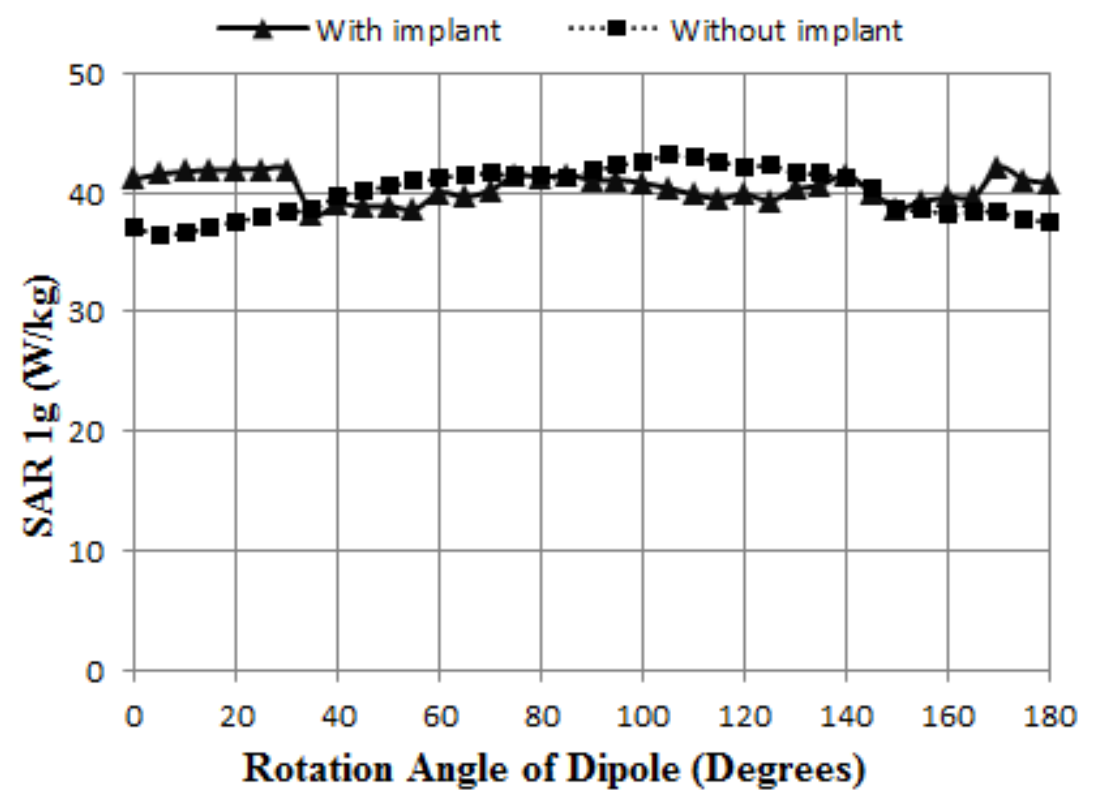

(a)

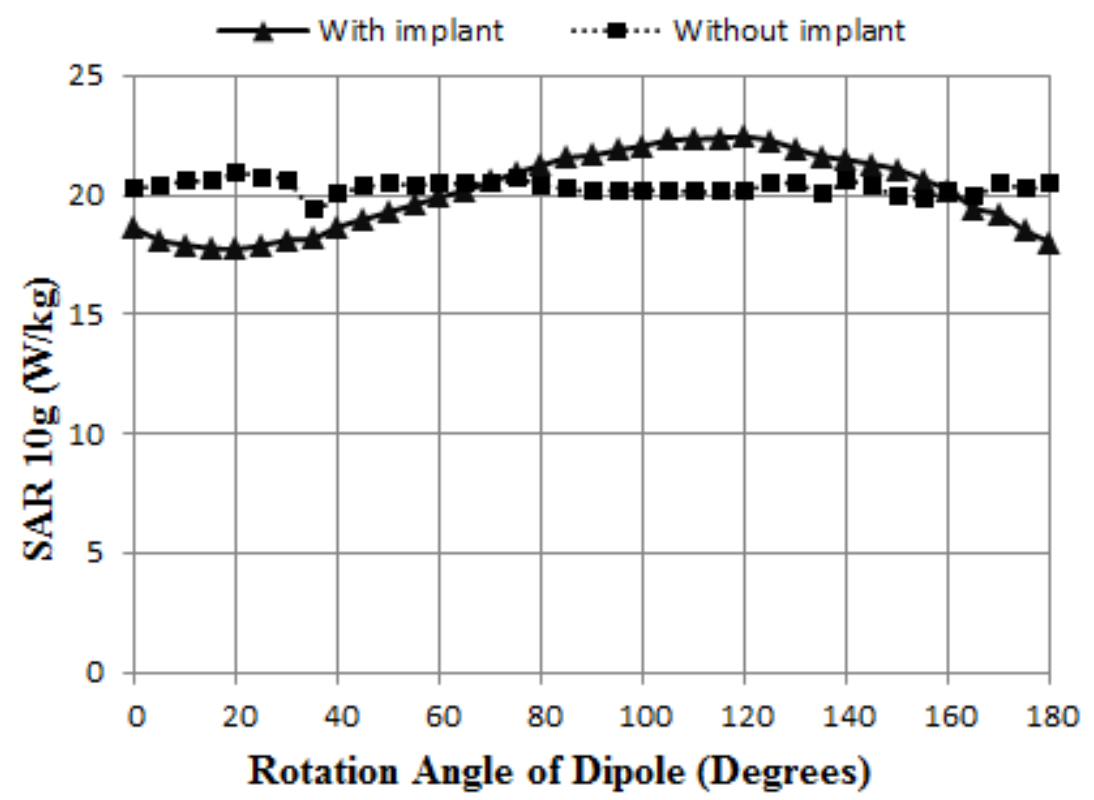

(b)

Figure 7. The maximum (a) $\mathrm{SAR}_{1 \mathrm{~g}}$ and (b) $\mathrm{SAR}_{10 \mathrm{~g}}$ as a function of dipole's rotation angle at $2100 \mathrm{MHz}$ for with and without implant.

It should be noted that this paper has quantified the relative enhancement factor of the implant. The SAR values with the dipole source are higher than allowed in the standards. This is partly due to the excitation being a continuous wave and the duty factor has not been considered, whereas other papers consider this and normalised to $0.125 \mathrm{~W}$ instead of $1 \mathrm{~W}$ as simulated in this paper. 


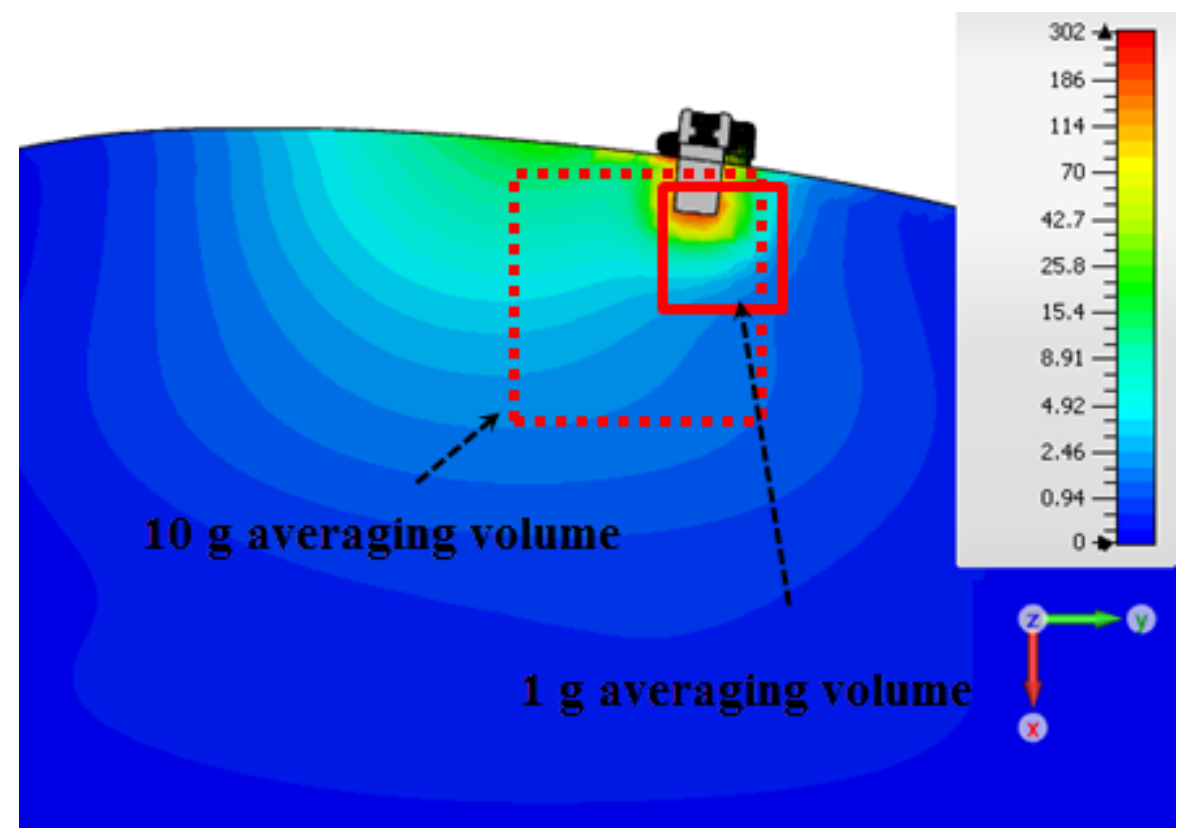

(a)

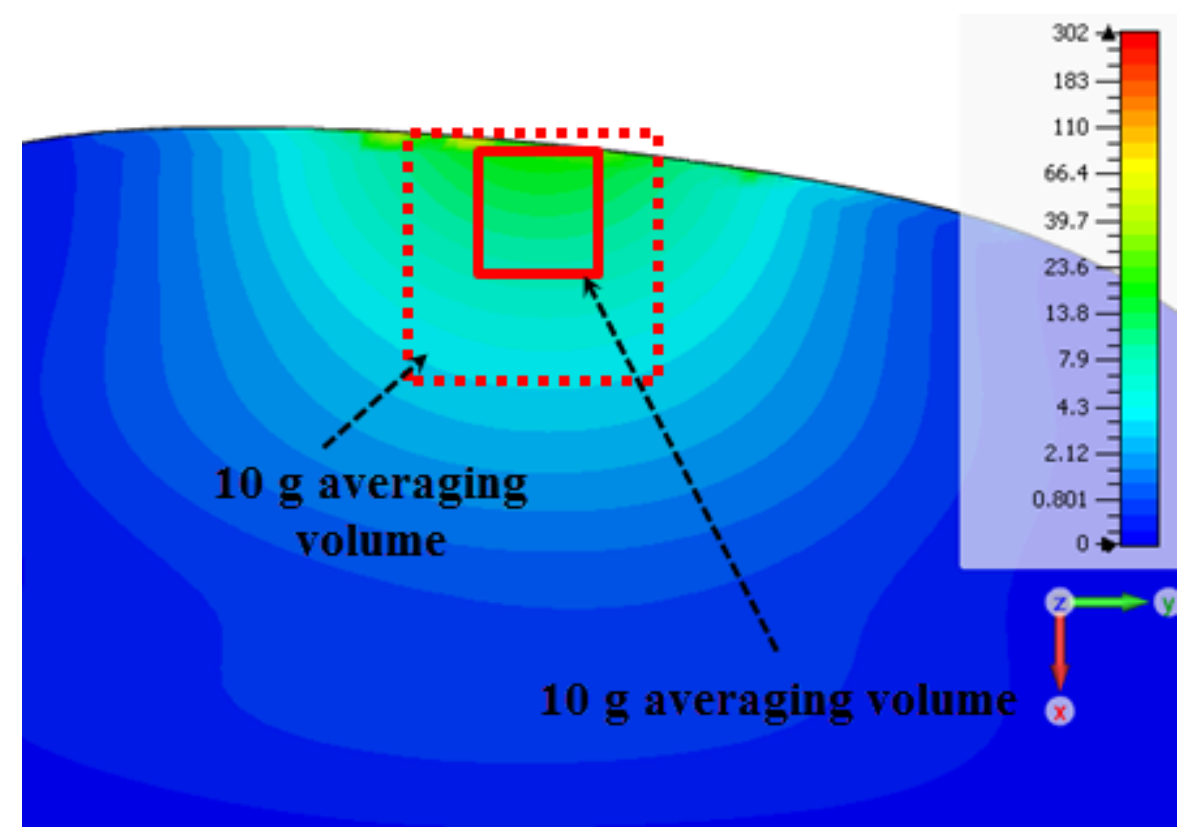

(b)

Figure 8. Distribution of local SAR through $\mathrm{x}-\mathrm{y}$ axis at $900 \mathrm{MHz}$ for the head (a) with and (b) without implant.

\section{CONCLUSIONS}

This paper has shown how the frequency and polarisation affect the SAR in the head due to a real metal implant. At $900 \mathrm{MHz}$, the implant doubled the $\mathrm{SAR}_{1 \mathrm{~g}}$ in the head when the dipole was vertical. The $\mathrm{SAR}_{1 \mathrm{~g}}$ was approximately doubled at 145 degrees at 
$1800 \mathrm{MHz}$, however, there was little affect at $2100 \mathrm{MHz}$ for all polarisations. This indicates the different sections of the implant resonate depending on the frequency and polarisation. These results demonstrate that this real implant is a complex scattering element. The implant focuses and reflects the incident RF energy. The half wavelength size is $16 \mathrm{~cm}$ at $900 \mathrm{MHz}$ and $8 \mathrm{~cm}$ at $1800 \mathrm{MHz}$. Note these lengths must be scaled by the square root of the permittivity of the shell. The nearby tissue of the head will also have a secondary dielectric loading effect. The relative enhancement on the $\mathrm{SAR}_{10 \mathrm{~g}}$ due to the implant was much smaller. The SAR distribution figures show that the increase in the SAR due to the metallic implant is extremely local to the implant. This explains the change in the $\mathrm{SAR}_{1 \mathrm{~g}}$ (which is averaged over an averaging volume with side length $1 \mathrm{~cm}$ ) and the much smaller changes to the ${ }_{10 \mathrm{~g}} \mathrm{SAR}$ (which is averaged over an averaging volume with approximately $2.2 \mathrm{~cm}$ side length). This study is confined to the analysis of near-field RF exposure. Future work will extend this study to plane wave studies for farfield RF exposures such as might be experienced by RF workers.

\section{References}

1. Brånemark P-I, de Oliveira MF. Craniofacial Prostheses: Anaplastology \& Osseointegration. 1st ed. Carol Stream IL, USA: Quintessence Publishing Co. Ltd; 1997. p. 101-110.

2. Prosthetic Ear Construction [Internet]. [cited 2014 Jan 28]. Available from: http://www.cartis.org/prosthetic-ear/.

3. Fleming AHJ, Lubinas V, Joyner KH. Calculation of Electric Fields in Tissue Near Metallic Implants. APMC Asia-Pacific Microw. Conf. Ieee; 1992;1:229232.

4. Lazzi G, Demarco SC, Liu W, Weiland JD, Humayun MS. Computed SAR and Thermal Elevation in a 0.25-mm 2-D Model of the Human Eye and Head in Response to an Implanted Retinal Stimulator Part II : Results. IEEE Trans. Antennas Propag. 2003;51:2286-2295. 
5. Mattei E, Calcagnini G, Censi F, Triventi M, Bartolini P. Radiofrequency dosimetry in subjects implanted with metallic straight wires: a numerical study. Conf. Proc. IEEE Eng. Med. Biol. Soc. 2008 Jan;2008:4387-4390.

6. McIntosh RL, Anderson V, McKenzie RJ. A numerical evaluation of SAR distribution and temperature changes around a metallic plate in the head of a RF exposed worker. Bioelectromagnetics. 2005 Jul;26:377-388.

7. McIntosh RL, Iskra S, McKenzie RJ, Chambers J, Metzenthen B, Anderson V. Assessment of SAR and thermal changes near a cochlear implant system for mobile phone type exposures. Bioelectromagnetics. 2008 Jan;29:71-80.

8. Olteanu M, Rafiroiu D. Temperature Increase due to Specific Absorption Rate Enhancement around Metallic Stent Implants. E-Health Bioeng. Conf.; 2011. p. $1-3$.

9. Parazzini M, Sibella F, Ravazzani P. Effect of a Cochlear Implant on the SAR distribution of the head exposed to $2.4 \mathrm{GHz}$. 20th Int. Zurich Symp. Electromagn. Compat. Ieee; 2009. p. 245-248.

10. Rafiroiu D, Ciupa R, Iancu A. Numerical analysis of the electric field and temperature changes around carotid stents. 7th Int. Symp. Adv. Top. Electr. Eng. 2011. p. 3-6.

11. Ruggera PS, Witters DM, Maltzahn G, Bassen HI. In vitro assessment of tissue heating near metallic medical implants by exposure to pulsed radio frequency diathermy. Phys. Med. Biol. 2003 Sep;48:2919-2928.

12. Sibella F, Parazzini M, Paglialonga A, Ravazzani P. Assessment of SAR in the tissues near a cochlear implant exposed to radiofrequency electromagnetic fields. Phys. Med. Biol. 2009 Apr;54:N135-N141.

13. Singh V, Qusba A, Roy A. Specific absorption rate and current densities in the human eye and head induced by the telemetry link of an epiretinal prosthesis. IEEE Trans. Antennas Propag. 2009;57:3110-3118.

14. Vidal N, López-Villegas JM. Changes in Electromagnetic Field Absorption in the Presence of Subcutaneous Implanted Devices: Minimizing Increases in Absorption. IEEE Trans. Electromagn. Compat. 2010 Aug;52:545-555.

15. Virtanen H, Huttunen J, Toropainen A, Lappalainen R. Interaction of mobile phones with superficial passive metallic implants. Phys. Med. Biol. 2005 Jun;50:2689-2700.

16. Virtanen H, Keshvari J, Lappalainen R. The effect of authentic metallic implants on the SAR distribution of the head exposed to 900, 1800 and $2450 \mathrm{MHz}$ dipole near field. Phys. Med. Biol. 2007 Mar;52:1221-1236. 
17. Virtanen $\mathrm{H}$, Keshvari $\mathrm{J}$, Lappalainen $\mathrm{R}$. Interaction of radio frequency electromagnetic fields and passive metallic implants-A brief review. Bioelectromagnetics. 2006 Sep;27:431-439.

18. Yu D, Zhang R, Liu Q. Influence of dentures on SAR in the visible Chinese human head voxel phantom exposed to a mobile phone at 900 and $1800 \mathrm{MHz}$. Bioelectromagnetics. 2012 Sep;33:508-517.

19. Zastrow E, Cabot E, Christ A, Kuster N. Experimental phantoms for the assessment of medical implant leads induced SAR under a linear-phase incident field condition. 2011 XXXth URSI Gen. Assem. Sci. Symp. Ieee; 2011. p. 1-4.

20. Cooper, J. Hombach V, Cooper J, Hombach V. Increase in specific absorption rate in human heads arising from implantations. Electron. Lett. IET; 1996 Nov;32:2217-2219.

21. Panagamuwa CJ, Whittow WG, Edwards RM, Vardaxoglou JC. A Study of the Effects of Metallic Pins on SAR using a Specific Anthropomorphic Mannequin (SAM) Head Phantom. Antennas Propagation, 2007. EuCAP 2007. Second Eur. Conf. IET; 2007. p. 1-6.

22. Mat MH, Malek MF, Whittow WG, Ronald SH, Zulkefli MS, Saudin N, Mohamed L. The influence of human head model wearing metal-frame spectacles to the changes of SAR and antenna gain: simulation of frontal face exposure. Prog. Electromagn. Res. 2013;137:453-473.

23. Whittow WG, Edwards RM. A Study of Changes to Specific Absorption Rates in the Human Eye Close to Perfectly Conducting Spectacles Within the Radio Frequency Range 1.5 to $3.0 \mathrm{GHz}$. IEEE Trans. Antennas Propag. IEE; 2004 Dec;52:3207-3212.

24. Whittow WG, Edwards RM, Panagamuwa CJ, Vardaxoglou JC. Effect of tongue jewellery and orthodontist metallic braces on the sar due to mobile phones in different anatomical human head models including children. 2008 Loughbrgh. Antennas Propag. Conf. IEEE; 2008. p. 293-296.

25. ICNIRP. Guidelines for limiting exposure to time-varying electric, magnetic, and electromagnetic fields (up to $300 \mathrm{GHz}$ ). Health Phys.. 1998;74:494-522.

26. IEEE. IEEE standard for safety levels with respect to human exposure to radio frequency electromagnetic fields, $3 \mathrm{kHz}$ to $300 \mathrm{GHz}$ IEEE Standards C95.1. 2005.

27. Kawai H, Ito K. Simple evaluation method of estimating local average SAR. IEEE Trans. Microw. Theory Tech. 2004;52:2021-2029. 